\title{
Using Wearable Devices to Stimulate Students Motor of Physical Activity and Consequence Physcological Responce
}

\section{Uso de dispositivos portátiles para estimular a los estudiantes el motor de la actividad física y la consecuencia de la respuesta fisiológica}

Aleksandr E. Stradze

Moscow City University, Moscow, Russia

ORCID: https://orcid.org/0000-0001-7264-8453

Valentina N. Pushkina

Moscow City University, Moscow, Russia

ORCID: https://orcid.org/0000-0002-7399-1998

Elena Yu. Fedorova

Moscow City University, Moscow, Russia

ORCID: https://orcid.org/0000-0002-2804-4158

Irina N. Gernet

Moscow City University, Moscow, Russia

ORCID: https://orcid.org/0000-0003-3952-0284

Andrei E. Sizov

Moscow City University, Moscow, Russia

ORCID: https://orcid.org/0000-0003-2826-8423

Aleksandr V. Emelianov

Moscow City University, Moscow, Russia

ORCID: https://orcid.org/0000-0002-8052-4706

Received 12-12-19 Revised 01-25-20 Accepted 04-14-20 On line 04-21-20

*Correspondence

Email: irinagernet@yandex.ru
Cite as:
Stradze, A. E., Pushkina, V. N., Fedorova, E. Yu., Gernet, I. N., Sizov, A. E., \& Emelianov, A. V. (2020). Using Wearable Devices To Stimulate Students Motor Of Physical Activity And Consequence Physcological Responce. Propósitos y Representaciones, 8(2), e510. doi: http://dx.doi.org/10.20511/pyr2020.v8n2.510 


\section{Summary}

They presented the results of qualitative and quantitative indicator study concerning the motor activity of schoolchildren of both sexes, obtained by using individual wearable devices-fitness trackers. It was found that $8.2 \%$ of students, regardless of gender and age, are characterized by low values of this indicator; $3.4 \%$ demonstrate high values of the indicator relative to the hygiene norm.

Keywords: Fitness Tracker; Physical Activity; Aerobic Zone; Anaerobic Zone; Maximum Oxygen Consumption.

\section{Resumen}

Presentaron los resultados del estudio de indicadores cualitativos y cuantitativos sobre la actividad motora de escolares de ambos sexos, obtenidos mediante el uso de dispositivos portátiles individuales: rastreadores de estado físico. Se encontró que el $8.2 \%$ de los estudiantes, independientemente de su sexo y edad, se caracterizan por valores bajos de este indicador; El $3,4 \%$ demuestra valores altos del indicador en relación con la norma de higiene.

Palabras clave: Rastreador de actividad física; Actividad física; Zona aeróbica; Zona anaeróbica, Consumo máximo de oxígeno.

\section{Introduction}

The formation of a healthy lifestyle of the nation, one of the fundamental factors of which is physical activity, has become a priority trend of the Russian state in the social sphere, requiring close attention not only of the health care system, but also of the education system.

Particular attention in the framework of state social policy is given to children and adolescent health improvement, the creation of favorable conditions for them, as well as raising the level of public awareness about the main risk factors and the ways of disease prevention. The use of physical education and the formation of physical culture since a very early age can be considered as one of the main components of such complex of preventive measures (Starostin, 2018).

Overcoming of intensive educational and cognitive activity negative consequences among schoolchildren must be considered as one of the links in the general system of physical education. In this regard, the issue of the purposeful development of the most important physical qualities among children, including physical activity, which can reduce the adverse effect of excessive educational loads on the health status of schoolchildren, is of practical interest. The study of student health status in conjunction with physical education is extremely important for preventive measure substantiation and strengthening the health of the younger generation (Butko, 2015; Galimov \& Mutalov, 2012: Pegov \& Tarasevich, 2013).

Wearable and digital technologies are an example of the latest technologies that have quickly burst into the life of a modern person, and designed to expand the knowledge of the body and its movements, the formation of "healthy" habits and lifestyle through this knowledge, especially among people belonging to the "risk group".

Constant monitoring of health indicators using individual wearable devices, fitness technology trackers allows not only to monitor the general condition of a person, but also to understand and prevent possible problems, as well as to track changes in the body performance 
(Sloan, Kim, Sahasranaman, Müller-Riemenschneider, Biddle, \& Finkelstein, 2018; Finkelstein, Haaland, Bilger, Sahasranaman, Sloan, Nang \& Evenson, 2016; Dawson, 2015).

Despite numerous works available in the domestic and foreign literature on the role of physical education in the development of schoolchildren, the monitoring of quantitative and qualitative characteristics of physical activity, including various metabolic loads for schoolchildren remains unexplored, which served the basis for this research.

\section{Methods}

A representative sample of 500 students of both sexes from general education organizations in Moscow was formed to conduct the study (Table 1).

Table 1.

Experimental sample

\begin{tabular}{llll}
\hline Age & Girls & Yong men & Total \\
\hline $8-9$ years & 93 & 112 & 205 \\
$10-11$ years & 93 & 88 & 181 \\
$12-13$ years & 38 & 59 & 97 \\
14 years & 11 & 8 & 19 \\
Total & 235 & 267 & 502 \\
\hline
\end{tabular}

Students with disabilities, people with disabilities, and people assigned to special medical groups were not involved in the study, taking into account their deterministic nosological features. Fitness trackers - individual wearable devices were used to organize and conduct the study, the form factor of which is a wrist polyurethane bracelet for daily use.

The hardware and software component of the fitness tracker and the user interface of the device corresponded to the Xiaomi Mi Band 3 model or similar models corresponding to the following characteristics:

- compatibility with iOS and Android;

- the presence of a vibration signal;

- the presence of moisture protection standard of at least IP68;

- water resistance class WR50 (shower, swimming without diving);

- the presence of a monochrome OLED touch screen;

- the presence of Bluetooth interface - at least 4.2 LE;

- the ability to monitor sleep, calories, physical activity automatically;

- the presence of accelerometer sensors, and built-in heart rate monitor;

- the presence of a non-removable Li-Ion battery with the capacity of at least 110 $\mathrm{mA} / \mathrm{h}$.

- Also, they used modern models of smartphones with installed software from the manufacturer of the fitness tracker to organize the study.

- The above-mentioned models of wearable devices are capable of capturing and processing the following parameters of physical activity:

- sleep duration and quality;

- heart rate (hereinafter - HR), including minimum, maximum, and average values; 
- number of steps;

- traveled distance (Hallinan \& Striphas, 2016; McGrath \& Scanaill, 2013; Millington, 2016).

Based on the data obtained, the device automatically calculates such parameters as the duration of load in the aerobic, anaerobic zone, the duration of physical work at the level of maximum oxygen consumption (hereinafter - MOC).

Current and operational control of physical exertion volume and intensity among students, taking into account all forms of physical education and sports (both in school and after school), was carried out for 30 calendar days by screening physiological indicators, including cardiac activity dynamics.

The most informative and productive mode of fitness tracker use is the following one: after carrying out appropriate instruction, students begin to use fitness trackers that are worn constantly, which is accompanied by a systematic collection and processing of data obtained using wearable data devices.

Statistical processing of the data obtained during the experiment was carried out using Microsoft Excel 2010 and Statistika 10.0 software. The confidence level of differences in the studied parameters was determined using Student's criterion. The results were considered statistically significant at $\mathrm{p} \leq 0.05$.

Study results. Body weight is one of the indicators that a fitness tracker takes into account for the correct processing and interpretation of signals, as well as determines the parameters of physical activity. Like age, this indicator cannot be tracked by the device on its own and is entered directly by the user in the corresponding software field. Of course, for a correct assessment of body weight correspondence to the age period, it is much more objective to use the body mass index. However, it is not taken into account in the corresponding device operation algorithms and is not evaluated in this study.

The normative boundaries were developed by the World Health Organization. At that they are defined without taking into account growth parameters and correspond to the age characteristics of girls and boys, which meets the objectives of the study. Also, the normative values are compared with the data array of the open segment of the Internet information and telecommunication network using Big Data (Data mining) technologies. At that no significant and statistically significant differences were found (Mayer-Schönberger \& Cukier, 2013; Volodin, Kalinkin, \& Kulikov, 2015; Grudina, 2012).

In this study, the median values for each age and gender are determined, the upper and lower limits of the norm are determined. Based on these data, the assessment of the body weight of schoolchildren of both sexes showed that the greatest significant $(\mathrm{p} \leq 0.001)$ excess of the age norm is typical for 14 year old adolescents $(62.5 \%)$, the smallest one - for 12-13 year old boys $10.2 \%$. A similar pattern was revealed in the groups of girls: the excess of the age norm is typical for the age of 14 years $-18.2 \%$, the smallest one is for the age of $12-13$ years $-2.6 \%$.

The presence of an accelerometer in the used models of fitness trackers made it possible to estimate the duration of sleep with a certain degree of certainty ( $\mathrm{p} \leq 0.01)$, according to the dynamics and normative values of which presented by the American Academy of Sleep Medicine, one can judge the degree of physical load sufficiency and adequacy, as well as about the mental state of a child, the general state of his health. In addition to the duration of sleep itself, the duration of the fast sleep phase, which is determined by the accelerometer on the basis of muscle vibrations during sleep and the decrease of heart rate, is essential. 
Studies have shown that about $50 \%$ of young men of all age groups (except for 14 year olds) have a sleep duration characterized by a lower limit of normal, at the age of 14 this indicator reaches $75 \%$. At that, the quality of sleep is within the normal range among $60 \%$ of young men of all age groups (except for 14 years old), at the age of 14 this indicator reaches $75 \%$. In groups of girls, there were no significant age-related differences in the duration of sleep; the number of examined patients, characterized by the value of this indicator at the lower boundary of the norm, as well as the median, was about $45 \%$. Sleep quality of about $70 \%$ of girls of all ages (except for 14 year olds) was within the medial range; $27.3 ; 36.4$ and $36.4 \%$ of 14 year old girls had the quality of sleep at median, lower bound and below normal, respectively.

The main parameter of physical activity, which is monitored with a fitness tracker by photometry and registration of electrochemical signals on human skin, is the heart rate. Heart rate is the most labile, informative and reliable parameter for physical activity evaluation, the level and nature of the functional load, as well as the most important parameter for use in device algorithm operation.

The digital algorithms of fitness trackers basically use the results of research in the field of sports physiology, one of which is the principle of physiological zoning, which consists in correlating the dynamics of the heart rate with the time during which exercise is performed. The range of heart rate will determine the physiological zone of physical work from the point of view of energy supply mechanism and the volume of energy consumption.

Using a fitness tracker allows you to track such parameters in automatic mode, keep track of received loads, set the necessary goals and monitor their achievement.

In the course of the study, we analyzed the data on physical work performed during the study period in terms of the length of stay in the following physiological zones:1) aerobic; 2) anaerobic; 3 ) the duration of physical work at the level of maximum oxygen consumption.

In order to obtain reliable information about the level of physical activity of students in general educational institutions, we analyzed the average duration of physical work in the aerobic zone per day for the study period. Such an approach will allow to take into account all types of physical activity, also to determine the contribution of a physical education lesson to the general level of physical activity. The obtained average data for 30 calendar days make it possible to assess the physical activity of students on a five-level scale, from low to high based on the average time per day when a student is in a supporting aerobic load zone (Figure 1; Figure 2; Table 2; Table 3; Table 4).

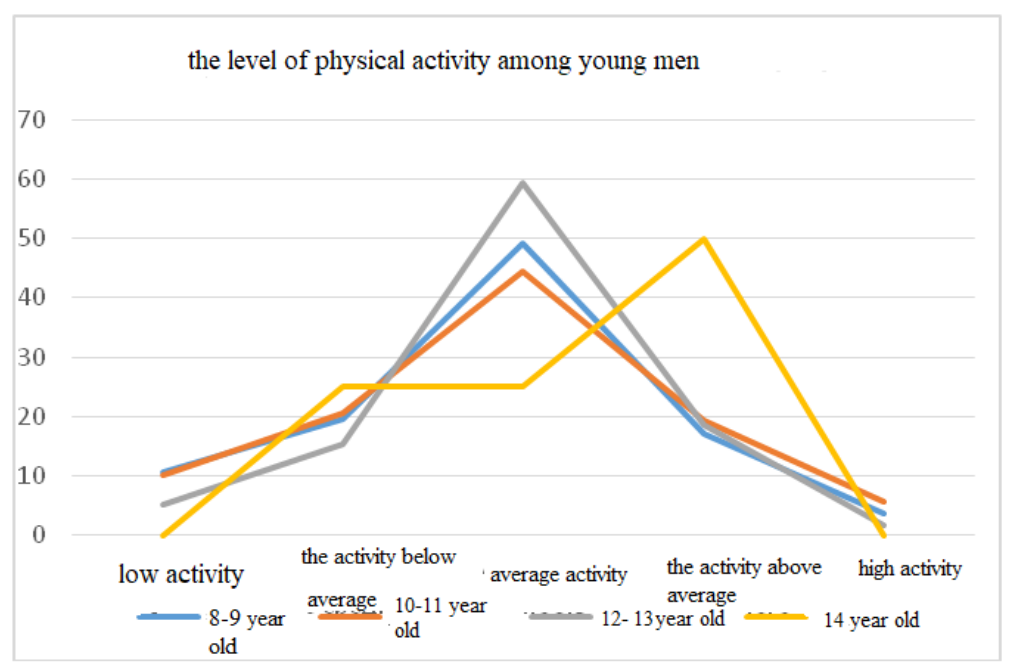

Figure 1. Physical activity level among young men, \% 


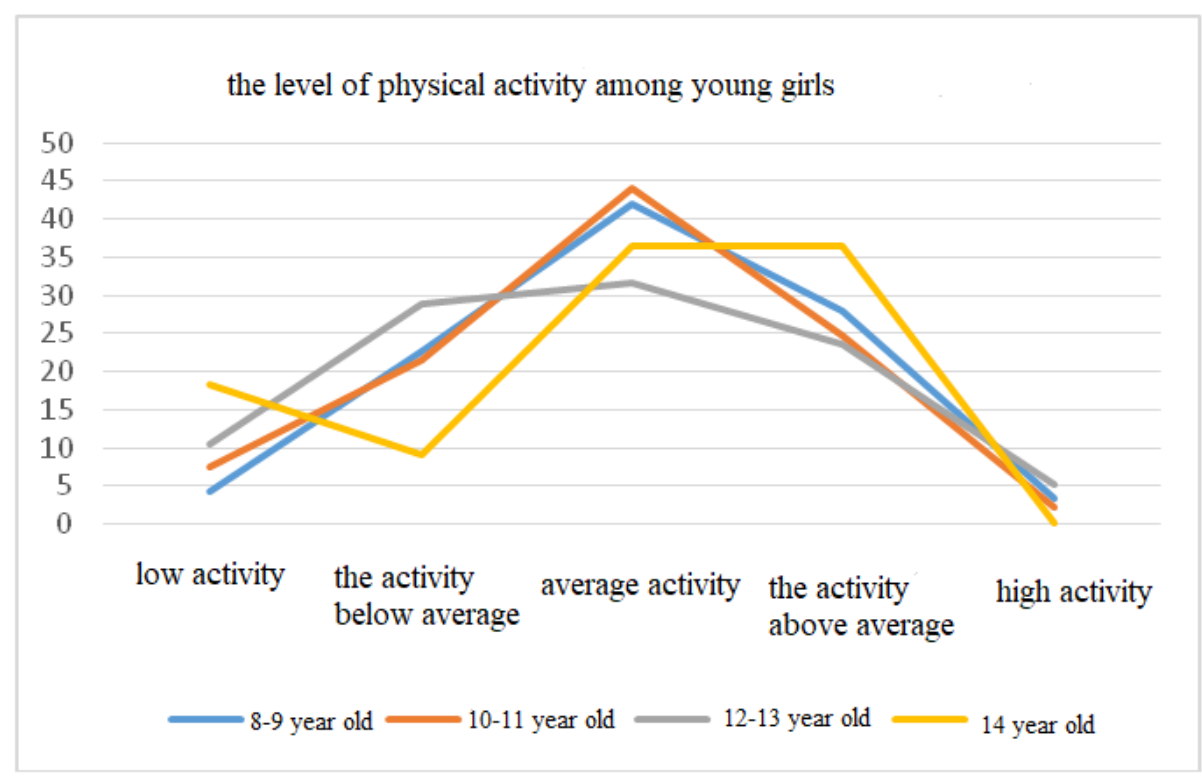

Figure 2. Physical activity level among girls, \%

Table 2.

The parameters of physical activity among students by age

\begin{tabular}{lllll}
\hline Sample parameters & \multicolumn{4}{l}{ Amount of students, \% } \\
\cline { 2 - 5 } & $8-9$ years & $10-11$ years & $12-13$ years & 14 years \\
\hline Low activity & 7,8 & 8,8 & 7,2 & 10,5 \\
Below average activity & 21,0 & 21,0 & 20,6 & 15,8 \\
Average activity & 45,9 & 44,2 & 48,5 & 31,6 \\
Above average activity & 22,0 & 22,1 & 20,6 & 42,1 \\
High activity & 3,4 & 0,0 & 0,0 & 0,0 \\
\hline
\end{tabular}


Table 3.

The parameters of physical activity among students regardless of age

\begin{tabular}{lllll}
\hline Parameter & $\begin{array}{l}\text { Young men } \\
\text { Number of students }\end{array}$ & Amount, \% & Number of students & Amount, \% \\
& 24,0 & 9,0 & 17,0 & 7,2 \\
\hline Low activity & 51,0 & 19,1 & 53,0 & 22,6 \\
$\begin{array}{l}\text { Below average } \\
\text { activity }\end{array}$ & & & \\
Average activity & 131,0 & 49,1 & 96,0 & 40,9 \\
$\begin{array}{l}\text { Above average } \\
\text { activity }\end{array}$ & 51,0 & 19,1 & 62,0 & 26,4 \\
High activity & 10,0 & & & 3,0 \\
Total & 267,0 & 3,7 & 7,0 & 100,0 \\
\hline
\end{tabular}

Table 4.

The parameters of physical activity by total sample array

\begin{tabular}{lll}
\hline Parameter & Number of students & Amount, \% \\
\hline Low activity & 41,0 & 8,2 \\
Below average activity & 104,0 & 20,7 \\
Average activity & 227,0 & 45,2 \\
Above average activity & 113,0 & 22,5 \\
High activity & 17,0 & 3,4 \\
Total & 502,0 & 100,0 \\
\hline
\end{tabular}

The studies allowed us to draw the following conclusions about the expediency of fitness tracker use to solve such interrelated tasks as:

- the implementation of current and operational control of student physical activity volume and intensity, taking into account all forms of classes;

- evaluation of physical fitness level of students and the adequacy of their physical activity for a selected period of time;

- individualization of physical education classes;

- assessment of planned educational result achievement.

The data on quantitative and qualitative characteristics of the physical activity of schoolchildren of both sexes, regardless of age obtained using fitness trackers, showed that $28.9 \%$ of the examined need to increase the duration of their physical activity, recommending take into account the number of steps performed per day using gadgets and individual fitness trackers, 
bringing individual indicators to hygiene standards - 15-20 thousand steps per day. Regular aerobic exercise of medium and low intensity in the amount of hygiene standards will allow students to improve the tolerance of physical and mental stress, mood and mental state, will help strengthen the cardiovascular and respiratory systems.

\section{References}

Butko, M. A. (2015). Pedagogical Technology for Motor Activity Regulation Among the Children of Primary School Age in the Educational Environment. The Dissertation for the degree of $\mathrm{PhD}$ in Pedagogics. Kaliningrad, Russia

Dawson, M. C. (2015). CrossFit: Fitness cult or reinventive institution?. International Review for the Sociology of Sport, 8(2), 1-19.

Finkelstein, E. A., Haaland, B. A., Bilger, M., Sahasranaman, A., Sloan, R. A., Nang, E. E. C., \& Evenson, K. R. (2016). Activity tracking effectiveness with and without incentives for increased physical activity (TRIPPA): randomized, controlled trial. Lancet Diabetes Endocrinol, 4(12), 983-995.

Galimov, R. R., \& Mutalov, A. G. (2012). The state of motor activity of schoolchildren in the modern conditions of their training and education. Medical Bulletin of Bashkortostan, 7(5), 211-218;

Grudina, S. V. (2012). The relevance of fitness technology introduction in the educational process of schoolchildren [Text]. Theory and practice of education in the modern world: materials of the II-nd Intern. scientific conf. (Saint-Petersburg, November 2012) - St. Petersburg: Renome, pp. 70-72.

Hallinan, B., \& Striphas, T. (2016). Recommended for you: The Netflix Prize and the production of algorithmic culture. New media \& society, 18(1), 117-137.

Mayer-Schönberger, V., \& Cukier, K. (2013). Big Data: A Revolution That Will Transform How WeLive, Work, and Think. New York: Houghton Mifflin Harcourt Publishing Company.

McGrath, M. J., \& Scanaill, C. N. (2013). Sensor Technologies: Healthcare, Wellness and Environmental Applications. Apress.

Millington, B. (2016). Fit for prosumption: interactivity and the second fitness boom. Media, Culture \& Society, 38(8), 1184-1200.

Pegov, V. A., \& Tarasevich, K. A. (2013). Conjugation of motor and intellectual development of children of primary school age. Problems of physical culture and sports development in the new millennium: Materials of the 2nd international scientific and practical conference (Ekaterinburg, March 7 2013) - Yekaterinburg, Federal State Autonomous Educational Institution of Higher Professional Education.

Sloan, R. A., Kim, J., Sahasranaman, A., Müller-Riemenschneider, F., Biddle, S. J., \& Finkelstein, E. A. (2018). The effect of a wearable tracking device for consumer activity on a sedentary period and prolonged sedentary seizures: the secondary analysis of randomized controlled trial. BMC Res Notes, 11(1), 189.

Starostin, V. P. (2018). The state policy of Russia aimed at healthy lifestyle development: the main trends for 10 years. International Journal of Applied and Basic Research, 5(1), 130137 ;

Volodin, K. I., Kalinkin, P. V., \& Kulikov, O. O. (2015). Development of a mobile application for a fitness tracker with the elements of gamification. Transactions of the International Symposium "Reliability and Quality", 2, 184-186. 